\title{
Um problema de taxonomia? Graphic Novels como literatura de testemunho: 0 caso de Art Spielgeman
}

\author{
A problem of taxonomy? Graphic Novels as testimonial literature: \\ The case of Art Spielgeman
}

\author{
Victor Callari \\ Doutorando em História Social pela Universidade de São Paulo \\ victorcallari@hotmail.com
}

Resumo: A Graphic Novel Maus: a história de um sobrevivente, de Art Speigelman, narra a trajetória de seu pai durante a ascensão do partido nazista na Alemanha na década de 1930 e sua passagem pelos campos de concentração. A obra foi agraciada com o prêmio Pulitzer e é, ainda hoje, considerada uma das narrativas mais importantes acerca da Shoah. O artigo analisa, a partir do problema da tensão entre a ficção e o real, a posição da obra diante da vasta literatura de testemunho produzida nas últimas décadas, seja diretamente pelos sobreviventes ou pela segunda geração. Os referenciais teóricos e metodológicos do estudo advêm das reflexões de François Hartog, Paul Ricoeur, Giorgio Agamben, Márcio Seligmann Silva e JeanPaul Gabilliet.

Palavras-chave: Graphic Novels, Memória e Testemunho, Segunda Guerra Mundial.

\begin{abstract}
The Graphic Novel Maus: a survival's tale, by Art Speigelman, tells the story of his father during the rise of the Nazi party in Germany in the 1930s and his passage through the concentration camps during the war, the piece was awarded with the Pulitzer Prize and is still considered one of the most important narratives about the Shoah. From the problem of the tension between fiction and reality, the article analyzes the position of the work in the face of the vast literature of testimony produced in the last decades, either directly by the survivors or by the second generation. The theoretical and methodological references of the study come from the reflections of François Hartog, Paul Ricoeur, Giorgio Agamben, Márcio Seligmann Silva and Jean-Paul Gabilliet.

Keywords: Graphic Novels, Memory and Testimony, Second World War.
\end{abstract}




\section{Introdução}

Em dezembro de 2008, a editora Berkley Books anunciou que não publicaria o aguardado livro Angel at the fence: the true story of a love that survived, escrito pelo sobrevivente e testemunha da Shoah ${ }^{1}$, Herman Rosenblat. O cancelamento trouxe à tona, mais uma vez, não apenas raivosos e inconsequentes negacionistas, mas principalmente o debate acerca dos limites entre a ficção e o real em obras literárias, em especial nas narrativas de memória, ou em obras que passaram a ser definidas a partir da alcunha de "literatura de testemunho" 2 .

Em sua obra, Rosenblat narrava sua experiência como prisioneiro no campo de concentração de Buchenwald, localizado próximo à icônica cidade de Weimar e construído ainda em 1937. Buchenwald foi um dos maiores campos de concentração construídos dentro do território alemão e possuía a capacidade de abrigar mais de oito mil pessoas. Entre sua abertura e o momento de sua liberação por tropas estadunidenses em 1945, abrigou prisioneiros políticos, judeus, eslavos, poloneses e também pessoas com problemas mentais. Segundo Rosenblat, a partir de 1944, ele recebeu ajuda de uma jovem judia de mais ou menos nove anos de idade. A jovem morava com sua família em uma fazenda nos arredores do campo e se disfarçava de cristã para não ser reconhecida pelos soldados alemães. Ainda segundo Rosenblat, a menina teria the passado uma maçã pela cerca e repetido essa ação com outros alimentos durante quase sete meses, sendo assim, a principal responsável por sua sobrevivência. $\mathrm{O}$ autor afirmou que em 1957, mais de uma década após a libertação do campo pelas tropas estadunidenses, ele e a jovem se reencontraram durante um "encontro às cegas", e que enquanto conversavam descobriram que partilhavam desse passado em comum e acabaram se casando.

A história descrita acima ganhou contornos públicos no início de 1995, quando Rosenblat participou de um concurso do The New York Post sobre as melhores histórias de amor enviadas por um leitor. No ano seguinte, Rosenblat e sua esposa, Roma Radzick Rosenblat, foram convidados a participar de um dos mais importantes

${ }^{1}$ O termo Shoah de origem hebraica, cujo significado é "devastação" ou "catástrofe", passou a ser utilizado preferencialmente ao termo Holocausto, que significa sacrifício em chamas, e que em sua etimologia remete alguma positividade em relação a um sacrifício feito para Deus. E ainda que não concordemos com o posicionamento de Agamben que afirma "Por isso, nunca faremos uso desse termo [Holocausto]. Quem continua a fazê-lo, demonstra ignorância ou insensibilidade (ou uma e outra coisa ao mesmo tempo)", optamos por manter o uso de Shoah.

${ }^{2}$ As noções de "testemunha" e testemunho" já foram largamente estudadas pelas Ciências Humanas em diálogos quase sempre interdisciplinares. Sugerimos os trabalhos de Paul Ricoeur (2007) em especial o capítulo intitulado "o testemunho", e do filósofo Giorgio Agamben (2008) com destaque para o capítulo "A testemunha". 
programas da televisão estadunidense, o The Oprah Winfrey Show, o que lhes garantiu maior visibilidade e prestígio.

O senhor Rosenblat recontou sua história repetidamente para jornais e revistas e para o autor do livro "sopa de galinha para a alma dos casais", publicado em 1999. A autora de livros infantis, Laurie Friedman, ficou tão inspirada por um artigo que ela leu online que ela escreveu um livro de crianças baseado em sua história. (RICH; STELTER.2008)³.

Foi Kenneth Waltzer, diretor do departamento de estudos judaicos da Universidade estadual de Michigan, o responsável por revelar que o romance, base de sustentação da narrativa de Rosenblat, era, de fato, uma farsa. Waltzer estava trabalhando em um livro sobre como cerca de 900 meninos haviam sobrevivido ao campo de Buchenwald e, aproveitando as circunstâncias, questionou alguns dos sobreviventes do campo, incluindo alguns garotos que foram levados junto com Rosenblat, acerca da história de amor que conquistava o público estadunidense. Os entrevistados afirmaram não acreditar na história da maçã (RICH; BERGER. 2008), mas reafirmaram Rosenblat como um sobrevivente de Buchenwald. A autoridade da "testemunha" parecia se afirmar. Contudo, a questão foi plenamente resolvida por Waltzer ao examinar "plantas" do campo de concentração desenhadas por alguns dos sobreviventes entrevistados. Nelas, ele identificou que todas as cercas eram adjacentes a outros subcampos com exceção de uma localizada na porção sul, e que poderia permitir alguma forma de contato externo. No entanto, esse contato seria impossível, pois a cerca ficava justamente ao lado do alojamento de soldados da SS. Além de todos esses elementos, Waltzer identificou que a família de Roma estava a mais de trezentos quilômetros de distância do campo.

Após ter sua história contestada, Rosenblat admitiu publicamente a farsa, mas sustentou sua "liberdade" criativa afirmando "foi a minha imaginação. E em minha mente, eu acredito nisso. Ainda hoje, eu acredito que ela esteve lá e que jogou a maçã

\footnotetext{
${ }^{3}$ Tradução livre: "Mr. Rosenblat retold his story repeatedly to newspaper and magazine reporters and to a writer for the book "Chicken Soup for the Couple's Soul," published in 1999. A children's author, Laurie Friedman, was so inspired by an online news article she read about the Rosenblats that she wrote a children's book based on his story." In: (RICH, STELTER, 2008)
} 
para mim" (HARRIS; O’KEEF; FERRAN. 2009) ${ }^{4}$. Segundo os jornalistas do NY Times responsáveis pela cobertura dos acontecimentos, Rosenblat recebeu apoio de pessoas próximas a ele e simpáticas a sua trajetória, mas também recebeu duras críticas no processo. O produtor cinematográfico Harris Salomon, interessado em produzir um filme a partir da história de Rosenblat, afirmou "se nós estivéssemos falando sobre os horrores do Holocausto e da vida nos campos de concentração estarem incorretos, seria algo completamente diferente, mas nós estamos debatendo uma maçã ter sido jogada por cima de uma cerca" (RICH; STELTER.2008) ${ }^{5}$, enquanto que Waltzer afirmou

ainda que eu aceite uma pluralidade de abordagens sobre o Holocausto, existem limites, e quando produtos culturais negam ou afastam as pessoas do que eu chamo de difícil conhecimento do Holocausto, então elas estão usando o Holocausto para seus próprios propósitos e não produzindo conhecimento sobre ele (BERNSTEIN, 2009) ${ }^{6}$.

Na visão de Salomon, a história da maçã, assim como o romance que sustenta sua narrativa, são detalhes que não invalidam a trajetória do autor como um sobrevivente da Segunda Guerra Mundial, enquanto que para Waltzer, a inserção de detalhes ficcionais em meio ao testemunho da Shoah poderia reforçar a visão de negacionistas que a cada dia se aproveitam do número menor de sobreviventes aptos a prestar testemunho e preservar a memória do extermínio do povo judeu. Nesse sentido, é possível afirmar que Angel at the fence: the true story of a love that survived figura ao lado de obras como Misha: a mémoire of the holocausto years, de Misha Defonseca, e Fragments: memories of a wartime childhood, de Binjamin Wilkomirski, publicadas, respectivamente, em 1997 e 1995 e que depois acabaram desmascaradas como fraudes.

Não foi apenas a literatura que enfrentou problemas ao tematizar os eventos da Segunda Guerra Mundial. Apenas alguns meses antes de atingir o ápice de sua carreira ao receber o prêmio Pulitzer pela obra "Maus: a história de um sobrevivente", o

\footnotetext{
${ }^{4}$ Tradução livre: "It was my imagination. And in my imagination, in my mind, I believed it. Even now, I believe it, that she was there and she threw the apple to me. ... In my imagination, it was true.". In.: (HARRIS; O'KEEF; FERRAN. 2009).

${ }^{5}$ Tradução livre: If we were talking about the horrors of the Holocaust and life in the concentration camp being incorrect, that would be something entirely different," Mr. Salomon said. "But we are debating an apple being thrown over the fence. In: ( RICH; STELTER. 2008).

${ }^{6}$ Tradução livre: "though I accept a plurality of approaches to the Holocaust. But there are limits, and when cultural products deny or lead people away from what I call the difficult knowledge of the Holocaust, then they're using the Holocaust for their own purposes and not creating knowledge about it." In: (BERNSTEIN. 2009).
} 
quadrinista Art Spiegelman teve uma carta publicada pelo jornal The New York Times, em sua seção The New York Review of books. A carta do artista era endereçada ao editor e intitulada "um problema de taxonomia". Nela é possível verificar não apenas um desabafo do autor acerca da classificação adotada pelo jornal para sua Graphic Novel, mas também uma forma de marcar uma posição acerca do real significado do testemunho presente em Maus.

\section{Para o editor:}

Eu gostaria de agradecer ao The Times por seu reconhecimento e apoio ao meu livro "Maus II". Fiquei muito feliz em vê-lo em sua lista de best-sellers (8 de dezembro). Eu nunca esperei que meu trabalho alcançasse essa proporção (meus ratos nunca se vestiram para o sucesso). No entanto, o encanto se transformou em surpresa quando notei que a obra apareceu na categoria de ficção do seu livro. Se sua lista fosse dividida em literatura e não-literatura, eu poderia aceitar graciosamente o elogio como pretendido, mas na medida em que "ficção" indica que um trabalho não é factual, eu me sinto um pouco indisposto. Como autor, creio que poderia ter poupado vários anos dos 13 anos que dediquei ao meu projeto de dois volumes, se pudesse ter tomado a licença de um romancista.

A fronteira entre ficção e não-ficção tem sido um território fértil para alguns dos textos contemporâneos mais potentes, e não é como se minhas passagens sobre como construir um bunker e consertar botas de campo de concentração dessem a credibilidade do livro para sua lista. É só que eu estremeço ao pensar como David Duke - se ele pudesse ler - responderia a ver um trabalho cuidadosamente pesquisado baseado nas memórias de vida do meu pai na Europa de Hitler e nos campos da morte classificados como ficção.

Sei que, ao delinear pessoas com cabeças de animais, criei problemas de taxonomia para você. Você poderia considerar adicionar uma categoria "nonfiction / mice" especial à sua lista? (SPIEGELMAN, 1991)7.

\footnotetext{
${ }^{7}$ Tradução livre: "To the Editor: I'd like to thank The Times for its recognition and support of my book "Maus II." I was delighted to see it surface on your best-seller list (Dec. 8). I never expected my work to reach such heights (my mice never dressed for success). Delight blurred into surprise, however, when I noted that it appeared on the fiction side of your ledger. If your list were divided into literature and nonliterature, I could gracefully accept the compliment as intended, but to the extent that "fiction" indicates that a work isn't factual, I feel a bit queasy. As an author I believe I might have lopped several years off the 13 I devoted to my two-volume project if I could only have taken a novelist's license while searching for a novelistic structure. The borderland between fiction and nonfiction has been fertile territory for some of the most potent contemporary writing, and it's not as though my passages on how to build a bunker and repair concentration camp boots got the book onto your advice, how-to and
} 
Se por um lado a literatura de testemunho tradicional parece não permitir que seus autores tomem liberdades criativas, tal qual a tomada por Rosenblat, por outro é inegável que o testemunho de Spiegelman tenciona os limites entre a ficção e o real, dessa forma, este artigo reflete acerca dessa tensão em um suporte como as histórias em quadrinhos. Primeiramente, procuramos introduzir o leitor no universo particular das Graphic Novels, em um segundo momento procuramos apresentar algumas das características do que hoje entendemos por literatura de testemunho, e em sua parte final apresentamos algumas considerações acerca da obra Maus e sua condição enquanto parte da literatura de testemunho.

\section{Graphic Novels: uma introdução necessária}

Ainda que o problema acerca de uma definição precisa das Graphic Novels seja bastante conhecido entre os pesquisadores das histórias em quadrinhos, ele deve ser novemente apresentado, uma vez que o próprio Art Spiegelman demonstrou descontentamento com o uso dessa expressão para definir sua obra (BAETENS, FREY, TABACHNICK, 2018). Evidentemente, o autor nem sempre é a pessoa mais apta a definir ou categorizar sua própria produção, contudo sua leitura não deve ser descartada ou desconsiderada sem uma reflexão que a sustente. O problema de Spiegelman com o termo Graphic Novel aparentemente não diz respeito ao termo em si, mas em sua aplicação para definir sua obra, pois acreditava que a expressão "novel”, entendida como "romance" ou "novela", poderia reforçar no leitor a compreensão de que Maus seria uma obra de ficção, desqualificando a expericência verdadeira de seu pai durante a Segunda Guerra Mundial. Em um primeiro momento, a leitura de Spiegelman parece absolutamente precisa, mas o mesmo raciocínio utilizado pelo autor permitiria questionar se Maus seria efetivamente uma obra produzida na linguagem das histórias em quadrinhos, já que em inglês a expressão equivalente seria "comic book", e Maus nem de longe pretende ser uma obra "cômica". Sabendo disso, devemos retornar ao termo Graphic Novel de forma a compreender sua historicidade e seus usos nas últimas cinco décadas para demonstrar porque Maus é, efetivamente, uma Graphic Novel.

miscellaneous list. It's just that I shudder to think how David Duke -- if he could read -- would respond to seeing a carefully researched work based closely on my father's memories of life in Hitler's Europe and in the death camps classified as fiction. I know that by delineating people with animal heads I've raised problems of taxonomy for you. Could you consider adding a special "nonfiction/ mice" category to your list? In: (SPIEGELMAN. 1991). 
Durante muito tempo o surgimento das Graphic Novels foi associado, erroneamente, à publicação da obra "Um contrato com Deus", de Will Eisner e publicada pela editora Baronet Books em 1978. Segundo essa tradição inventada, Eisner utilizou a expressão com o intuito de diferenciar sua obra das histórias em quadrinhos tradicionais, associadas à uma "literatura" infantil e sem qualidades artísticas. Contudo, pesquisas recentes apontam para a obra Beyond Time and Again, de George Metzger, comercializada pela primeira vez dois anos antes, em 1976, como a primeira Graphic Novel publicada, além de que essa denominação de primeira "Graphic Novel americana" teria sido feita em novembro de 1973, pelo fanzine Wonderworld ${ }^{8}$ fazendo referência à obra. Segundo Gabilliet ${ }^{9}$ :

A relação entre esse fanzine e a obra que seria publicada era seu editor, Richard Kyle, o homem que utilizou pela primeira vez as palavras "graphic novel" para intitular o que ele chamou de "tira em quadrinhos artisticamente séria", na "newsletter" da Comics Amateur Press Association, chamada Capa-Alpha 2, em novembro de 1964 (GABILLIET, 2018) ${ }^{10}$.

É possível verificar que tanto a tradição que coloca Eisner como o pioneiro das Graphic Novels, quanto a que atribui esse pioneirismo ao editor Richard Kyle, reforçam a ideia de que as Graphic Novels representariam não apenas um objeto cultural novo, mas também superior aos quadrinhos tradicionais, fosse por seu formato, seus espaços de comercialização, ou mesmo por seu conteúdo, maior, mais complexo e direcionado ao público adulto e não mais o público infanto-juvenil ${ }^{11}$. Essa leitura é

\footnotetext{
${ }^{8}$ É importante destacar e reconhecer que as pesquisas e os debates acerca de qual obra teria sido a "primeira" Graphic Novel contribuíram para o entendimento dos usos do termo, mas também é importante perceber que na maior parte das vezes, o debate, em especial quando realizado por pesquisadores de outras áreas como a comunicação, ou a tradução, e que não mantém diálogo com pressupostos teóricos e metodológicos do conhecimento histórico, tem por objetivo o desejo de encontrar marcos fundadores, procedimento que diz muito mais acerca do presente e suas necessidades do que propriamente do objeto em questão e suas respectivas historicidades. O problema dos "ídolos de origens" foi explicado por Marc Bloch em sua obra Apologia da História.

${ }^{9}$ As citações de Gabilliet e também de Baetens, Frey e Tabachnick foram todas retiradas da obra The Cambridge History of Graphic Novels, em uma versão digital, no formato e-book que não consta paginação nem outra forma de numeração/localização do texto. Por essa razão essas citações são referenciadas sem suas páginas específicas.

${ }_{10}$ Tradução livre: The conection between this fanzine and the forthcoming book was their publisher, Richard Kyle, the man who had first used the words "graphic novel" to name what he called "the artistically serious "comic book strip" in Capa-Alpha 2 (November 1964), the newsletter of the Comics Amateur Press Association. (GABILLIET, 2018)

${ }^{11}$ A ideia de que as histórias em quadrinhos eram lidas apenas por crianças também faz parte de uma tradição inventada e que vem sendo desmistificada por pesquisadores de diferentes áreas. Mark Kelley afirma que "Research suggests that, during the Golden Age, comic books had a large cultural base of
} 
defendida não apenas por Jean-Paul Gabilliet, mas também por Jan Baetens, Hugo Frey e Stephen Tabachinick ao afirmarem

Como se pode inferir da nossa exposição histórica, as Graphic Novels apresentam conteúdos que são semanticamente próprios para adultos. Em particular, autobiográficos, história, reportagens de notícias e ficção histórica - estas são algumas das preocupações dominantes (BAETENS, FREY, TABACHNICK, 2018) $)^{12}$.

Independente de quaisquer tradições inventadas que buscam consolidar pioneiros, as Graphic Novels emergiram em um contexto específico e que está relacionado ao movimento de quadrinhos underground do final da década de 1960. Em termos editoriais, as histórias em quadrinhos estavam enfrentando três grandes dificuldades. A primeira dizia respeito à queda no número de exemplares vendidos de seu principal gênero, o dos super-heróis. A segunda dificuldade estava relacionada ao Comics Code, um instrumento de autoregulação das editoras que procurava manter o conteúdo das histórias em consonância com os valores conservadores da sociedade estadunidense do pós-guerra, evitando que as revistas publicassem conteúdos que demonstrassem extrema violência, nudez, drogas, ou mesmo que atentassem contra a moral das classes médias; na prática o Comics Code representou uma forma de censura dos conteúdos que restringia a capacidade criativa dos artistas e acabou por infantilizar as histórias em quadrinhos. A terceira dificuldade era um problema intrínsico à própria indústria, e a forma como ela havia, desde antes da guerra, organizado seu sistema de produção, fazendo com que os artistas trabalhassem sempre com prazos apertados, que as histórias fossem fruto de um trabalho em que o desenhista era responsável por desenhar roteiros escritos por terceiros, e as histórias sempre sujeitas ao interesse comercial sob a supervisão de um editor, mas tão importante quanto a liberdade criativa

many ages. A Yank Weekly article, published in November of 1945, cited the estimates of the Market Research Company of America, which found that about 70 million Americans, roughly half of the U.S. population, read comic books. The ages of readers heavily favored children, with 95 percent of all boys and 91 percent of all girls between the ages of six and eleven reading comic books. The study also revealed a high percentage of adult readers, with 41 percent of men and 28 percent of women aged eighteen to thirty admitting to regularly reading comics. This impressive study proves that, in the Golden Age, comic books were not limited to children". (KELLEY, 2009: 1).

12 Tradução livre: As one can infer from our historical exposition, Graphic Novel features content that is registered for an semantically valiant for adults. In particular, autobiographical, history, news reportage, historical fiction - these are some of the dominant concerns. In: (BAETENS, FREY, TABACHNICK, 2018). 
estavam os direitos sobre as obras. Aos artistas contratados pelas editoras não era reservado nenhum direito sobre aquilo que eles escreviam ou desenhavam, nem mesmo às reimpressões das obras eram pagas novamente.

Nesse sentido, no final da década, a geração dos Baby-boomers, que havia recentemente atingido sua maturidade e professava suas insatisfações sociais e políticas por meio de linguagens como o cinema, a literatura e a música, também chegou às histórias em quadrinhos. Os artistas dessa nova geração se uniram a outros artistas já consagrados e deram início a um movimento de publicação underground de títulos que não chegavam sequer a cinco mil exemplares, e o pagamento pelo trabalho realizado, quando feito, não ultrapassava os U\$25,00, enquanto que as editoras mainstream chegavam a pagar até o dobro desse valor (GABILLIET, 2018). Para esses artistas, o que estava em jogo era sua liberdade de criação e o direto de propriedade de suas obras. Esse movimento chamado por Rosenkranz de "comix revolution" (ROSENKRANZ, 2008) deve ser entendido "no contexto de um fenômeno mais amplo, mais "subterrâneo", a conquista da auto-expressão como um componente pleno de arte na indústria de quadrinhos"(GABILLIET, 2018) ${ }^{13}$.

Os artistas do movimento underground começaram a encontrar espaços com maior liberdade criativa já em meados da década de 1950, em especial na revista "Mad", de William Gaines e seu editor Harvey Kurtzman. Mad foi uma publicação que resistiu ao código de censura ao modificar seu formato de publicação ainda nos primeiros anos do código, atingindo, assim um público mais velho do que as revistas de quadrinhos tradicionais. Na década de 1960, a liberdade criativa se expandiu e contou com a participação do editor James Warren, responsável pelkos títulos Help! (19601965), Creepy (1964-1983) e Eerie (1966-1983). No início da década de 1970, a ruptura com os modelos da industria mainstream se consolidou enquanto alguns artistas que participavam dos "comix" se voltaram para a "não ficção" e começaram a produzir obras em outros "gêneros", em especial, autobiográficas, reportagens e com temáticas históricas. A necessidade de valorização dos trabalhos e sua emancipação social da industria mainstream levou a criação e popularização das Graphic Novels.

\footnotetext{
${ }^{13}$ Tradução livre: "The emergence of underground comics must be replaced in the context of a broader, more "subterranean" phenomenon, the conquest of self expression as a full-fledged component of artistry in the comic book industry". In: (GABILLIET, 2018).
} 


\section{Maus, de Art Spiegelman e a literatura de testemunho}

No começo da década de 1990, Art Spiegelman finalizou aquela que é considerada sua obra seminal, a premiada Graphic Novel "Maus". O trabalho iniciado em 1978 e publicado em dois volumes, o primeiro "a história de um sobrevivente" compilado pela editora Penguin Books, em setembro de 1986, após sua publicação mensal nas páginas da revista $R a w$, editada pelo próprio autor e sua esposa desde o início da década, e o segundo "Maus: e foi aí que meus problemas finalmente começaram" foi finalizado apenas em 1991.

Desde a publicação do primeiro volume, ainda em 1986, Maus já havia se destacado entre as Graphic Novels e se tornou um sucesso não apenas de público e crítica, mas também despertou o interesse de pesquisadores no mundo todo. Segundo Philip Smith

Art Spiegelman é um dos artistas mais estudadoes nos "Comic Book Studies". The Bonner Online-Bibliographie Zur Comicforschung lista quase 350 artigos sobre Spiegelman, o que significa que dentro do campo dos Estudos de Quadrinhos, em termos de grande quantidade de interesse crítico, ele é superado apenas por Alan Moore. Sua obra ganhadora do Pulitzer, Maus (1980 e 1991), está presente regularmente em clubes do livro, nos currículos escolares do ensino médio, bem como nos cursos de graduação e pós-graduação e no cursos sobre quadrinhos e literatura acerca do Holocausto. Isso não é surpreendente; Maus foi ao lado The Dark Knight Returns (1986) e Watchmen (1987) o catalisador para uma mudança radical na comercialização e críticas das revistas em quadrinhos alternativas em meados da década de 1980. Tem tem sido um marco no discurso crítico sobre quadrinhos desde então (SMITH, 2015: 499) ${ }^{14}$.

\footnotetext{
${ }^{14}$ Tradução livre: "Art Spiegelman is one of the most-discussed creators in Comic Book Studies. The Bonner Online-Bibliographie Zur Comicforschung lists almost 350 articles on Spiegelman which means that, within the field of Comics Studies, in terms of sheer quantity of critical interest, he is exceeded only by Alan Moore. His Pulitzer-winning work Maus (1980 and 1991) features regularly in book clubs, high school literature syllabi, as well as under- and post-graduate courses on both comics and Holocaust literature. This is hardly surprising; Maus was, alongside The Dark Knight Returns (1986) and Watchmen (1987), the catalyst to a sea change in the commercial and critical fortunes of the alternative comic book during the mid-1980s. It has been a landmark text in critical discourse on comics ever since". In: (SMITH, 2015).
} 
Entre as inúmeras questões suscitadas pela obra, duas delas acabaram por se destacar, a opção do artista por representar personagens antropomorfizadas e o debate acerca do gênero da obra ser biográfico ou autobiográfico.

Sobre a representação antropomorfizada das personagens, a escolha de Spiegelman é vista, muitas vezes, como uma homenagem do artista ao personagem Mickey Mouse e ao seu criador, Walt Disney. A primeira publicação de Maus aconteceu em 1972 na revista Underground, Funny Animals. Umas das exigências editoriais da revista era de que as histórias publicadas tivessem apenas animais que pudessem falar. Nessa primeira versão de Maus, o personagem principal é um ratinho de nome Mickey e que ouvia seu pai contar histórias sobre um momento de seu passado em que grandes gatos perseguiram sua espécie.

Além daquilo que pode ser visto como uma homenagem feita pelo artista, é importante destacar que a epígrafe escolhida por Spiegelman para abrir o primeiro volume de Maus, "os judeus são, sem sombra de dúvidas, uma raça, mas não são humanos" (SPIEGELMAN, 2009: 10), frase dita por Adolf Hitler, pode ser uma ferramenta para ajudar a compreender a escolha do artista de representar as personagens de forma antropomorfizada. Nesse sentido, a opção de Spiegelman parece criticar a perspectiva nazista que separava os povos e as nações por raças, e enxergava na raça ariana uma raça superior. A opção do artista por trabalhar a obra em preto e branco também é muito importante, segundo Rosani Ketzer Umbach e Carla Carine Gerhardt

Nas civilizações ocidentais, o preto tem significado de aflição, morte, tristeza e solidão. A cor preta é associada a objetos pesados, sons desagradáveis, angústia, opressão, medo, pânico, inibição e ódio. É depressiva, solene, profunda e dominante. Tudo isso confere à história um tom sombrio, expressando o contexto negativo e dramático vivenciado pela família durante a ditadura nazista. Essa não utilização de cores nos desenhos imprime, pois, um sentido intrínseco à história de Vladek, demonstrando o quão terrível foi o período do nazismo em sua trajetória (UMBACH; GERHARDT, 2013: 54).

E por mais que a perspectiva das autoras pareça acertada, entendemos que a opção do artista pelo preto e branco tinha como objetivo reafirmar o caráter factual de sua narrativa, aproximando sua obra de uma visualidade muito utilizada pela linguagem cinematográfica dos documentarios que, em muitos casos, recorre ao filtro preto e 
branco, ou ainda imagens de épocas passadas como forma de reafirmação de um pretenso caráter verídico da narrativa. Em termos estéticos, o uso do preto e branco pode remeter também ao expressionismo do cinema alemão das décadas de 1920, movimento que influenciado pelas teorias de Nietzsche e Freud criticava o racionalismo moderno.

Spiegelman parece também antecipar alguns dos problemas que suas escolhas poderiam acarretar, tal qual mencionado na introduçao de nosso texto e exposto em sua carta "um problema de taxonomia". Dessa forma, a presença das fotografias de seu irmão Richieu e sua mãe Anja, ao se misturarem aos desenhos da linguagem dos quadrinhos, mais uma vez, servem de alerta ao leitor de que Maus se trata de uma narrativa verdadeira, mesmo que as personagens sejam retratadas como animais (ver imagem 1).

Imagem 1: Fotografias de Richeiu e Anja

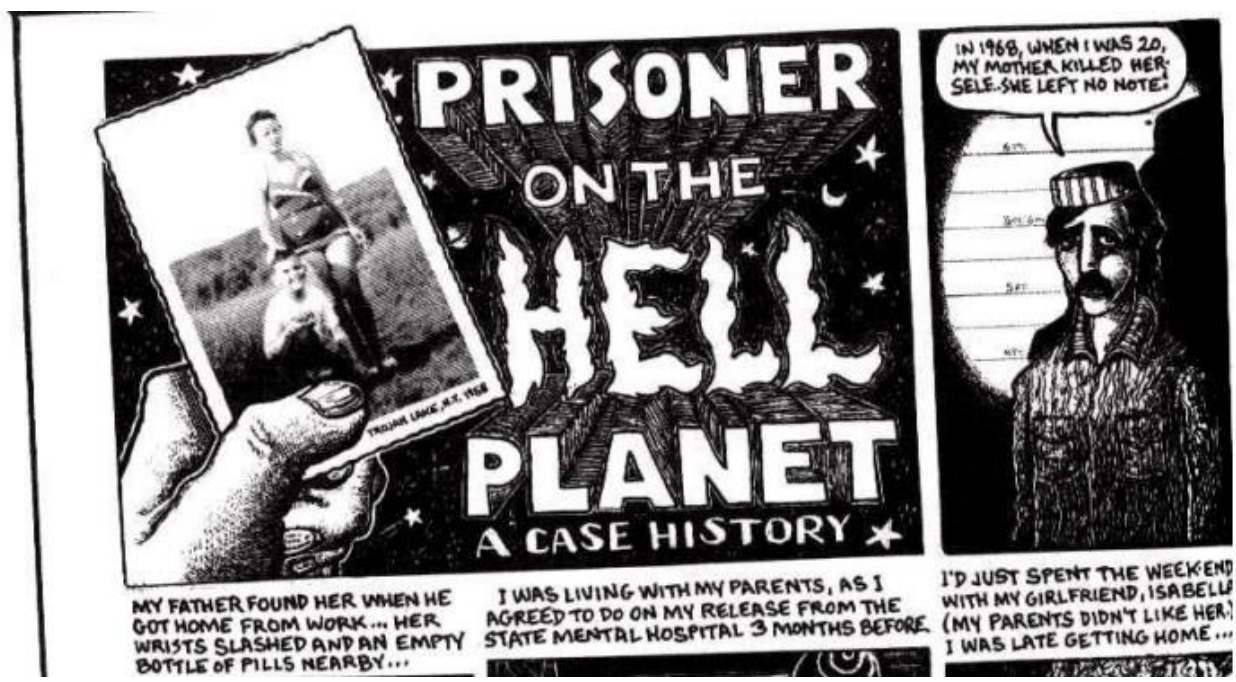

Fonte: Spiegelman, Art. Maus: a survivor's tale, p.100.

O segundo ponto diz respeito a obra ser considerada um relato biográfico criado pelo artista a partir das entrevistas que ele mesmo realizou com seu pai, Vladek Spiegelman, ao longo dos anos. Em seu relato, Vladek narra o período que vai de “meados da década de 1930 até o inverno de 1944”. Sua narrativa versa principalmente sobre como conheceu a mãe de Art, Anja, e como os dois sobreviveram durante a ascensão da Alemanha nazista e sua passagem no campo de concentração e extermínio de Auschwitz. Entretanto, muitos leitores e pesquisadores passaram a ver "Maus" como uma obra tanto biográfica quanto autobiográfica (McGLOTHLIN, 2018; 
NASCIMENTO, 2012), uma vez que a história é contada em duas temporalidades distintas, a do tempo narrado por Vladek, e a do tempo presente, que demonstra o próprio artista entrevistando o pai (ver imagem 2) e tendo que lidar com seus problemas pessoais, sejam aqueles relacionados à sua família, como o suicidio de sua mãe alguns anos após a guerra, a presença ausente de seu irmão morto e o difícil relacionamento com o próprio pai, ou os problemas decorrentes do sucesso alcançado a partir da publicação do primeiro volume em 1986. Nesse sentido, enquadrar a obra de Spiegelman como uma obra de biografia ou autobiografia apresenta inúmeros desafios aos estudiosos que sobre ela se debruçam, uma vez que cada um deles faz a opção por enfatizar a temática da Shoah presenta nos relatos de Vladek, ou os desafios enfrentados pelo artista.

Imagem 2: Art entrevistando seu pai

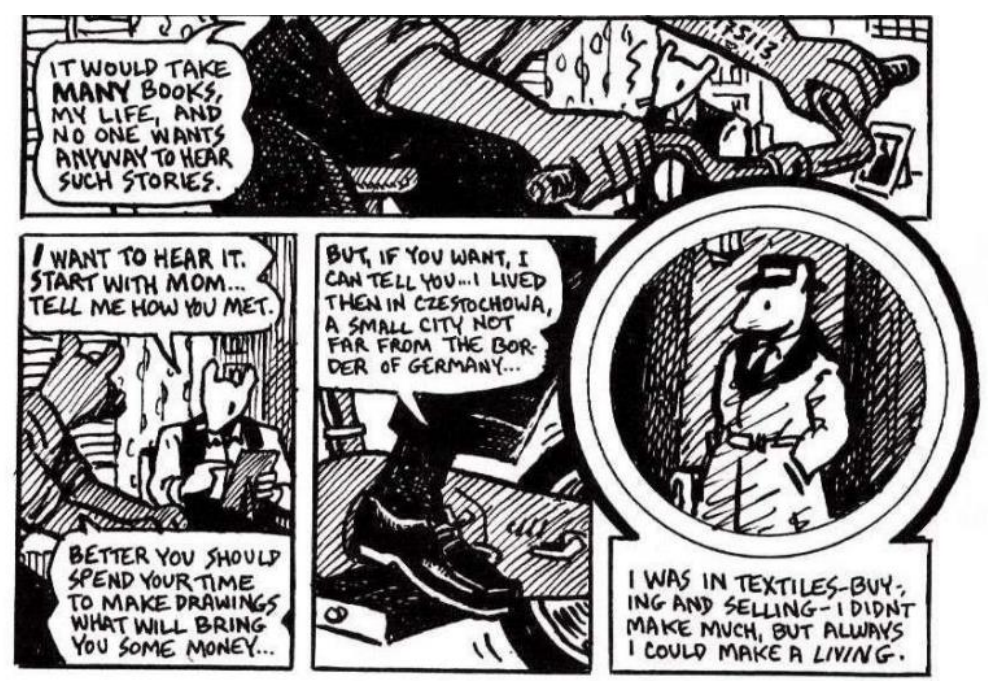

Fonte: Spiegelman, Art. Maus: a survivor's tale, p.12

Para além das duas primeiras questões levantadas, a obra de Spiegelman suscita também o debate acerca das condições do testemunho e das suas possibilidades de representação, uma vez que o testemunho de eventos traumáticos, especialmente aqueles relacionados à Shoah, são vistos também pela impossibilidade de sua narração.

Repito, não somos nós, os sobreviventes, as autênticas testemunhas. Esta é uma noção incômoda, da qual tomei consciência pouco a pouco, lendo as memórias dos outros e relendo as minhas, muitos anos depois. Nós, sobreviventes, somos uma minoria anômala, além de exígua: somos aqueles que, por prevaricação, habilidade ou sorte, não tocamos o fundo. Quem o fez, quem fitou a górgona, não voltou para contar, ou voltou mudo; mas são 
eles, os "muçulmanos", os que submergiram - são eles as testemunhas integrais, cujo depoimento teria significado geral. Eles são as regras, nós, a exceção (LEVI, 1990: 47).

A dificuldade da linguagem em representar o trauma expressa por Levi foi explicada por Seligmann-Silva:

A experiência traumática é, para Freud, aquela que não pode ser totalmente assimilada enquanto ocorre. Os exemplos de eventos traumáticos são batalhas e acidentes: o testemunho seria a narração não tanto desses fatos violentes, mas da resistência à compreensão dos mesmos. A linguagem tenta cercar e dar limites àquilo que não foi submetido a uma forma no ato de sua recpção. Daí Freud destacar a repetição constante, alucionatória, por parte do "traumatizado" da cena violenta: a história do trauma é a história de um choque violente, mas também de um desencontro com o rela (em grego, vale lembrar, "trauma" significa ferida). A incapacidade de simbolizar o choque o acaso que surge com a face da morte e do inimaginável - determina a repetição e a constante "posterioridade", ou seja, a volta, après-coup da cena (SELIGMANN-SILVA, 2013: 48-49).

Dessa forma, não basta refletir apenas sobre o significado do ato de testemunhar, mas se faz fundamental refletir acerca das condições de elaboração do testemunho e sua "confiabilidade". Para Paul Ricoeur "com o testemunho inaugura-se um processo epistemológico que parte da memória declarada, passa pelo arquivo e pelos documentos e termina na prova documental" (RICOEUR, 2007: 170). Para o autor, o testemunho implica uma relação não apenas entre aquele que testemunha e o evento relatado, mas também entre aquele que recebe o testemunho. Segundo Ricoeur:

Essa estrutura dialogal do testemunho ressalta de imediato sua dimensão fiduciária: a testemunha pede que lhe dêem crédito. Ela não se limita a dizer: "Eu estava lá", ela acrescenta: "Acreditem em mim". A autenticação do testemunho só será então completa após a resposta em eco daquele que recebe o testemunho e o aceita; o testemunho, a partir desse instante, está não apenas autenticado, ele está acreditado (RICOEUR, 2007: 171). 
Essa dimensão fiduciária mencionada por Ricoeur está intrinsecamente relacionada ao testemunho, e não apenas ao testemunho contemporâneo, pois em latim, testemunha pode ser ao mesmo tempo, testes e superstes, a primeira indicando a presença de uma terceira pessoa em um processo, o que reforça a questão da confiabilidade destacada por Ricoeur, enquanto que a segunda indicaria uma pessoa que "passou por uma provação" (SELIGMANN-SILVA, 2013: 374).

Spiegelman não é superstes, essa condição é de seu pai, Vladek. Spiegelman enquanto artista é o responsável pelas escolhas de representação do testemunho dentro da obra, os planos, os enquadramentos, as sarjetas - aqueles espaços entre os quadros que permitem ao artista controlar a leitura de seu leitor e ao mesmo tempo criar um espaço aberto para que o leitor preencha a partir de sua própria imaginação o tempo que decorre entre um quadro e outro - as tramas que compõem o enredo, entre tantos outros. Essa dimensão artística, criadora, potencializada em Maus na representação das personagens antropomorfizadas foi o ponto central do debate com o editor do The New York Review of books. E por mais que as escolhas de Spiegelman apareçam permeadas de liberdades artísticas, ele se preocupa com a veracidade de sua representação. Suas inúmeras viagens à Polônia para estudar o campo de concentração e extermínio de Auschwitz reafirmam seu comprometimento, assim como sua carta resposta ao jornal que questiona a categorização entre ficção e não-ficção.

\section{Considerações finais}

A ascensão dos testemunhos e da memória na sociedade contemporânea deve ser entendida como um dos sintomas do processo de aceleração do tempo e da ruptura promovida por aquilo que François Hartog denominou de um novo Regime de Historicidade, intitulado "presentismo". Para Hartog, o Regime de Historicidade consiste em uma ferramenta heurística de análise das relações que as socidades e homens mantém com o tempo em um determinado contexto. Indubitavelmente os eventos traumáticos do século passado, em especial a Shoah, contribuiram para a ascensão dos fenômenos do testemunho e da memória. A literatura de testemunho se firmou como um importante gênero narrativo do século XX. Suas condições de produção, sua relação com a sociedade e com o conhecimento acadêmico nas ciências humanas ainda estão sendo investigados. O debate acerca do testemunho, parece ainda 
transitar entre concepções positivistas e pós-modernas, dificultando um espaço intermediário de reflexão que permita situá-lo em suas delicadas posições. No caso específico da obra Maus, por mais que a condição artística da obra de Spiegelman possa, muitas vezes, suscitar dúvidas sobre sua precisão, questionando assim sua confiabilidade, o extrondoso sucesso comercial inibiu as mais duras críticas que a tensão entre a ficção e o real poderiam susctiar. Da mesma forma, as reflexões acerca do testemunho parecem, desde sempre, lidar com o problema da dúvida e das incertezas. No entanto, reconhecer o caráter literário da obra de Spiegelman não significa afirmar que histórias em quadrinhos são literatura. Concordamos com Paulo Ramos e outros pesquisadores que reforçam que os quadrinhos são uma linguagem autônoma e que partilham de elementos comuns, não apenas com a literatura, mas também com o cinema e as artes visuais. Ainda que Maus tensione até os limites a representação do passado a partir dos testemunho do pai do artista, a obra faz parte do canône da literatura de testemunho.

Roney Cytrynowicz ao realizar uma importante defesa do papel da história para o entendimento dos processos históricos contemporâneos e que contam com suas testemunhas como principais fontes, afirmou

Não devemos esperar do testemunho que ele explique algo, não não devemos fazer-lhe perguntas nem inquiri-lo sobre a história, mas apenas garantir-lhe o direito de falar, de contar. O testemunho do sobrevivente precisa ter seu valor, mas é preciso não deixá-lo jamais sozinho, para que sua experiência não se torne a voz da desesperança ou a expressão de questões de identidade ou política que a distanciem da história. Tampouco podemos tornar a voz dos sobreviventes a voz da consciência democrática e pluralista, a voz que tem a responsabilidade de tornar legível esta história (CYTRYNOWICZ, 2013: 136).

\section{Referências Bibliográficas}

AGAMBEN. Giorgio (2008). O que resta de Auschwitz: o arquivo e a testemunha. São Paulo: Boitempo.

BAETENS, Jan; FREY, Hugo; TABACHNICK, Stepehen (orgs.) (2018). The Cambridge History of the Graphic Novels. New York, NY: Cambridge University Press, versão digital (kindle).

BERNSTEIN, Richard. Holocaust facts and fictions. The New York Times, jan.02, 2009. <https://www.nytimes.com/2009/01/02/world/americas/02ihtletter.3.19054246.html >. Acesso em: 24 fev. 2019.

CYTRYNOWICZ, Roney (2013). O silêncio do sobrevivente: diálogo e rupturas entre memória e História do Holocausto, pp.123-139. In: SELIGMANN-SILVA, 
Márcio (org.) (2013). História, Memória e Literatura: o testemunho na era das catástrofes. Campinas, SP. Editora da Unicamp.

GABILLIET, Jean-Paul (2018). Underground Comix and the invention of autobiography, History, and Reportage. In: BAETENS, Jan; FREY, Hugo; TABACHNICK, Stepehen (orgs.). The Cambridge History of the Graphic Novels. New York, NY: Cambridge University Press, versão digital (kindle).

HARRIS, Dan. O'KEEF, Brian. FERRAN, Lee. Exclusive: Holocaust faker speaks out. ABCNews, feb.18, 2009. Disponível em < https://abcnews.go.com/GMA/US/story?id=6903068\&page=1\&page=1 >. Acesso em: 24 fev. 2019.

HARTOG, François (2013). Evidência da História: o que os historiadores veem. Belo Horizonte, MG. Editora Autêntica.

. (2017) Crer em História. Belo Horizonte, MG. Editora Autêntica, 2017.

- (2013) Regimes de historicidade: presenteísmo e experiências do tempo. Belo Horizonte, MG. Editora Autêntica.

KELLEY, Mark (2009). The Golden Age of Comic Books; Representations of American Culture from the Great Depression to the Cold War. Milwaukee, Wosconsin, ePublications@Marquette.

LEVI, Primo (1990). Os afogados e os sobreviventes. Rio de Janeiro: Paz e Terra.

McGLOTHLIN, Erin (2003). No time like the present: narrative and time in Art Spiegelman's Maus. Narrative Volume 11, number 2, may. disponível em < https://muse.jhu.edu/article/42265/pdf >, acesso em 24 fev. 2019.

NASCIMENTO, Larissa Silva (2012). Para além das cercas de arame farpado: o Holocausto em Maus, de Art Spiegelman, e em Os emigrantes, de W. G. Sebald. Dissertação de mestrado (pós-graduação) - Universidade de Brasília, Instituto de Letras, Departamento de Teoria Literária e Literaturas.

RICH, Motoko. STELTER, Brian (2008). As another memoir is faked, trust suffers. The New York Times, dec.30,Disponível em < https://www.nytimes.com/2008/12/31/books/31opra.html >, acesso em: 24 fev. 2019.

RICOEUR, Paul (2007). A memória, a história, o esquecimento. Campinas, SP. Editora da Unicamp.

ROSENKRANZ, Patrick (2008). Rebel Visions: the underground Comix Revolution, 1963-1975. Seattle, Washington. Fantagraphics Books.

SELIGMANN-SILVA, Márcio (org.) (2013). História, Memória e Literatura: o testemunho na era das catástrofes. Campinas, SP. Editora da Unicamp.

SMITH, Philip (2015). Spiegelman Studies Part 1 of 2: Maus. Literature Compass 12/10, pp.499-508.Disponível em < https://onlinelibrary.wiley.com/doi/pdf/10.1111/lic3.12262 >, acesso em: $28 \mathrm{fev}$. 2019.

SPIEGELMAN, Art (1991). A problem of taxonomy. The New York Times, dec.29. Disponível em < https://www.nytimes.com/1991/12/29/books/l-a-problem-oftaxonomy-37092.html >, acesso em: 24 fev. 2019.

. (2009) Maus: história completa. São Paulo, Companhia das Letras.

UMBACH, Rosani K.; GERHARDT, Carla C (2013). Uma leitura de Maus: a história de um sobrevivente. Revista Eletrônica Literatura e Autoritarismo, $\mathrm{n}^{\circ} 22$ - julho a dezembro, pp.46-55. Disponível em:< https://periodicos.ufsm.br/LA/article/view/12972/pdf >, acesso em: 28 fev. 2019. 
Artigo recebido em 10 de março de 2019.

Aprovado em 19 de maio de 2019.

DOI: 10.12957/intellectus.2019.43927 